\title{
LAS NUEVAS FORMAS DE TURISMO RECEPTIVO EN URUGUAY. ESTUDIO DE CASO DE LAS ESTADIAS POR ESTUDIOS DE MAESTRIIA Y DOCTORADO (2005-2010)
}

\author{
NOVAS FORMAS DE TURISMO RECEPTOR NO URUGUAI. ESTADA DE ESTUDANTES DE MESTRADO \\ E DOUTORADO COMO ESTUDO DE CASO (2005-2010) \\ NEW FORMS OF RECEPTIVE TOURISM IN URUGUAY. A CASE STUDY OF MASTER'S AND PHD \\ STUDENTS (2005-2010)
}

Silvia Facal Santiago sfacals@gmail.com Profesora e Investigadora de la Facultad de Ciencias Empresariales (UDE) Doctora en Historia por la Universidad de Santiago de Compostela Máster en Inmigración por la Universidad Pontificia Comillas de Madrid Especialista en Gestión de Empresas Turísticas por la Universidad Politécnica de Madrid Licencia en Historia por la Universidad de la República

Manuel Díaz Molina mdiaz@ude.edu.uy

Profesor e Investigador de la Facultad de Ciencias Empresariales (UDE) Doctor en Medioambiente y Recursos Naturales por la Universidad de Santiago de Compostela Máster en Ecoauditorías y Planificación Empresarial del Medioambiente Ingeniero Agrónomo por la Universidad de la Frontera

Ana Carolina P. Villalta

Alumna de intercambio en la Facultad de Ciencias Empresariales (UDE) BBA in Tourism and Recreational Management Degree por la Vancouver Island University.

Fecha de Sumisión: 29/11/2012

Fecha de Aprobación: 06/09/2013

\section{RESUMEN}

El turismo se ha convertido en la primera década del siglo XXI en Uruguay en una importante actividad económica generadora de divisas, debido al aumento del turismo receptivo internacional que escoge visitar este país del Cono Sur de América. Las formas adoptadas por este turismo receptivo internacional se encuadran en las tradicionales de sol, playa y termas -turismo recreativo- y también en otras nuevas entre las cuales destacan las estadías por estudios. En este artículo se analizan precisamente estas últimas tomando como punto focal el caso de las estadías por estudios de postgrado -de Maestría y Doctoradorealizadas por estudiantes brasileños a través de un enfoque metodológico cuantitativo al cual se le ha aplicado un análisis estadístico descriptivo acompañado de interpretaciones provenientes del campo de teóricos de la temática del turismo. Las mismas han presentado un importante aumento de llegadas entre los años 2005 y 2010 y se vislumbra que seguirán dicha tónica, logrando con ello un aumento en el gasto medio durante sus estadías.

PALABRAS CLAVE: Nuevas formas de turismo receptivo. Estadías por Estudios. Maestría. Doctorado. Uruguay. 
O turismo no Uruguai se tornou, na primeira década do século XXI, uma importante atividade econômica geradora de divisas devido ao aumento do turismo receptor internacional, que escolhe este referido país do Cone Sul como receptivo. As formas adotadas por este turismo receptor internacional se enquadram nas tradicionais de sol e mar e turismo termal - turismo recreativo - e também outras formas, dentre elas, a estada de estudos. Este artigo analisa esta última, tomando como foco o caso de estadas de estudos de pós-graduação - mestrado e doutorado - realizadas por estudantes brasileiros. O enfoque metodológico é quantitativo, ao qual foi aplicada uma análise descritiva estatística, acompanhada de interpretações provenientes da temática do campo teórico do turismo. Estas interpretações apresentaram como resultado um significativo aumento no receptivo entre os anos de 2005 a 2010, vislumbrando que seguirão esta tônica, tendo com isso um aumento no gasto médio dos estudantes de pós-graduação durante suas estadas.

PALAVRAS-ChAVE: Novas formas de turismo receptor. Estada de estudo. Mestrado. Doutorado. Uruguai.

\begin{abstract}
In Uruguay, in the first decade of the 21st Century, tourism has become an important economic activity, generating income through the increase in receptive tourism, with many international tourists choosing to travel to this country in the South Cone region. The forms adopted by this international receptive tourism are the traditional Sun, sea and sand and thermal springs i.e. recreation tourism, and also new forms, such as study trips. This article analyses this latter form of receptive tourism, focusing on study trips by Brazilian postgraduate students (master's degree and $\mathrm{PhD}$ ). It uses as quantitative methodological approach, with the application of a descriptive statistical analysis, accompanied by interpretations from the theoretical field of tourism. These interpretations presented a significant increase in the number of arrivals between 2005 and 2010, a rate that is expected to continue, leading to an increase in average expenditure among postgraduate students during their trips.
\end{abstract}

KEYWORDS: New forms of receptive tourism. Studies. Master's degree. PhD. Uruguay

\title{
INTRODUCCIÓN
}

Uruguay $^{1}$, en el último tercio del siglo XX se ha convertido en un destino preferencial del turismo regional y en menor medida del internacional en todas sus modalidades, gracias a una activa política de captación de turismo implementada a través del programa Uruguay Natural del Ministerio de Turismo y Deporte (MINTURD).

En este estudio nos enfocaremos únicamente en las nuevas formas adoptadas por el turismo receptivo internacional con especial énfasis en las estadías por estudios debido al aumento que en los últimos años se ha venido vislumbrado que las mismas tienen en Uruguay y debido también a la falta de estudios abordando las mismas. Por turismo receptivo se entiende el de los no residentes que viajan dentro del país (OMT, 1995), en este caso se trataría de los visitantes extranjeros o uruguayos residentes en el exterior que visitan el país, sea cual sea el motivo de su viaje, siempre y cuando los primeros no vengan en calidad de inmigrantes y los segundos no regresen a residir de forma definitiva (DÍAZ PELLICER, 2004). Las formas adoptadas por el turismo receptivo internacional se encuadrarían, a grandes rasgos, según la clasificación adoptada por la Organización Mundial

1 País ubicado de forma estratégica en el Cono Sur de América bañado por las aguas del Río Uruguay, del Río de la Plata y del Océano Atlántico. 
del Turismo (OMT) en: sol y playa (forma tradicional de masas), deportivo, de aventura (junto con el deportivo se presenta como una forma no tradicional de carácter más elitista), de naturaleza, rural (muy relacionada y junto con el turismo de naturaleza presentan una importante vinculación con la protección al medioambiente), cultural, urbano (forma no tradicional de reciente auge junto con el cultural, vinculados con los recursos patrimoniales), cruceros (en aumento en determinadas regiones), parques temáticos (de gran crecimiento tras la creación de Disney Orlando) y de reuniones y conferencias (OMT, 2002). A las mismas se les suele sumar en la actualidad las siguientes: negocios, industrial, científico, médico, salud y belleza, religioso, gastronómico, enológico, idiomático e incluso espacial o de compras (COOPER ET. AL, 1997; CÁRDENAS, 1999; KOTLER, BOWRN Y MAKENS, 2007; PLANTUR, 2010; RODRÍGUEZ DARIAS, SANTANA TALAVERA Y DÍAZ RODRÍGUEZ, 2010). Sin embargo, existen otras opciones aún no adecuadamente contempladas ni por la OMT ni por otras clasificaciones, 0 que simplemente tienden a diluirse en las estadísticas en algunas de las formas citadas anteriormente, como las estadías por estudios acompañadas de visitas turísticas o turismo de educación (MARTín ROJO, 2009). Se podría decir que existen tantas formas de turismo como motivos de viajes hay. El MINTURD realiza, en cambio, una clasificación más restrictiva de las mismas, englobándolas todas ellas bajo la denominación de motivos de viaje y agrupándolas en las siguientes formas: visita a familiares o amigos (muy común entre los emigrantes uruguayos residentes en el exterior), recreativo-paseo (englobaría la forma tradicional de sol y playa y también la termal), negocios y motivos profesionales, deportivo, estudios (estarían englobadas también la concurrencia a seminarios, congresos y cursos de corta duración), salud, tránsito, compras, segunda residencia, religioso, y otros (MINTURD, 2011). En esta clasificación está comprendida la estadía por estudios como un motivo de viaje incluido dentro de las entradas de turismo receptivo internacional, y eso es lo novedoso de la misma, pues en otras clasificaciones, salvo en la citada de Martín Rojo (2009), figura bajo otras formas de turismo no tradicional. No se debe olvidar que el turismo, en su concepción amplia, comprende las actividades que realizan las personas durante sus viajes y estancias en lugares distintos al de su entorno habitual, por un período consecutivo inferior a un año y mayor a un día, con fines de ocio, por negocios o por otros motivos (OMT, 2008), por tal motivo todos los motivos de viaje señalados por el MINTURD, incluidas las estadías por estudios, comprenderían actividades turísticas.

El denominado turismo recreativo, el cual incluiría en nuestro país las formas tradicionales de turismo receptivo internacional encabezadas por las de sol y playa, ha sido el predominante hasta la actualidad y tiene la particularidad de presentar una gran estacionalidad (BRIDA; LANZILOTTA y RISSO: 2008) con picos altos durante el verano y la semana de turismo (Semana Santa). No obstante, en el periodo transcurrido entre 2005 y $2010^{2}$ han tenido un considerable aumento las formas de turismo receptivo internacional no tradicionales como las de visitas a familiares o amigos, negocios, deportivo, estudios, salud y otros.

El principal objetivo de este estudio es, por lo tanto, confirmar una serie de hipótesis de las cuales partimos al inicio de la investigación, relacionadas con las formas de turismo no tradicional y en concreto con una de ellas, las estadías por estudios realizadas por estudiantes internacionales, centrando el foco en las estadías realizadas por estudiantes brasileños de postgrado de Maestría y Doctorado en Educación, Derecho y Ciencias Empresariales en un centro universitario privado del país, la Universidad de la Empresa (UDE) ${ }^{3}$ :

- Las estadías por estudios han experimentado el mayor aumento entre todas las formas de turismo receptivo internacional no tradicional entre 2005 y 2010 en Uruguay.

- Los estudiantes brasileños que han realizado estudios de postgrado de Maestría y Doctorado en la UDE entre 2005 y 2010 han efectuado un gasto medio mayor al realizado por el turista tradicional (brasileño) en nuestro país, reflejado en rubros como alojamiento, alimentación, vestimenta, objetos artesanales, libros y electrónica debido a que presentan una selectividad en su nivel educativo, socio-económico y de ingreso, muy superior al de la media de la población residente en Brasil y al de la media de los turistas brasileños.

2 Aún no se han publicado las cifras correspondientes al año 2011 en su totalidad, por eso aquí utilizamos únicamente hasta el año 2010.

3 Universidad privada creada en 1998 bajo el auspicio de la Asociación de Dirigentes de Marketing del Uruguay (ADM). Es la única universidad uruguaya que brinda cursos de postgrado en exclusiva a extranjeros en las citadas áreas de estudios. 
Si se comparan los estudios en turismo con la evolución de otras disciplinas de las ciencias sociales, se puede afirmar que los mismos son bastante recientes; recordemos que tan solo han pasado unos 120 años desde la aparición de la obra de Stradner (1884) en la cual el autor se ocupaba por primera vez del estudio y análisis tanto de los establecimientos como de los medios de prestación de servicios de los servicios turísticos. Este estudio y los sucesivos (Von Shullen, 1911; Hunziker \& Krapf, 1942, entre otros) se solían realizar en el contexto de la economía y por tal motivo presentaban análisis de la oferta y la demanda (Capanegra, 2007). Incluso la incorporación de la temática del turismo en los estudios universitarios es bastante tardía. Si nos atenemos, por ejemplo, a los países de nuestra región, recién a partir de la década de 1970 los mismos comienzan a tener presencia en las universidades de administración y economía. A partir de ese momento es cuando se puede decir que empiezan a consolidarse grupos de investigación también sobre la temática del turismo y se va construyendo un corpus de investigación en turismo cuya meta es el logro del reconocimiento académico por parte de sus pares de las otras ciencias sociales como campo disciplinario. Incluso se han realizado importantes investigaciones en materia turística fuera del ámbito universitario por parte de organismos internacionales como la OMT o de los propios Estados interesados en conocer las potencialidades de los mismos en la captación del turismo y sus divisas.

Si tuviéramos que evaluar los estudios realizados tanto en el ámbito académico como en el no académico en nuestra región, se los podrían enmarcar en tres grandes categorías: estudios estadísticos, de marketing y de corte sociológico (Campodónico y Chalar, 2011). De este modo, la tendencia ha sido la de describir de forma cuantitativa variables tales como el origen de los turistas, los gastos que efectúan o los niveles de ocupación de los diversos destinos, sin presentar un adecuado marco metodológico y conceptual de referencia.

Sin embargo, a partir de la década del 90 del siglo pasado, se ha producido un importante cambio en la investigación en turismo a través de la elaboración de un marco teórico de la materia. Pero para la realización del mismo, se hace necesario primero dar una serie de definiciones clave como la de turismo y al mismo tiempo mostrar el cambio de visión y/o comportamiento del turista con relación al destino visitado.

En la actualidad existe una amplia variedad de definiciones sobre turismo, debido al hecho de que, como manifiesta Gurría (1991), "se trata de una abstracción de la cual todos tenemos distintas interpretaciones". Nosotros empezaremos con la clásica de la OMT, que lo define como "las actividades que realizan las personas durante sus viajes y estancias en lugares distintos al de su entorno habitual, por un período de tiempo consecutivo inferior a un año, con fines de ocio, por negocios y otros motivos (OMT, 1995: 1). Sin embargo, se hace necesario recurrir también a otras definiciones para completar la misma como, por ejemplo, la de Valencia o la de Bull. El primero de los autores define el turismo "como el fenómeno resultante de una red de impactos socioeconómicos, culturales y ambientales generado por el desplazamiento y permanencia temporal de personas que, teniendo entre otros motivos la recreación y el descanso, visitan lugares que ofrecen bienes y servicios para la realización de actos particulares de consumo (Valencia, 1989). Y, desde una perspectiva netamente económica, Bull (1991: 11) sostiene que "el turismo no es ni un fenómeno ni un simple conjunto de industrias. Es una actividad humana que abarca el comportamiento humano, el uso de recursos y la interacción con otras personas, economías y entornos. También implica el movimiento físico de los turistas a lugares distintos de donde viven habitualmente. Aunque la mayor parte del turismo de todo el mundo es una forma de esparcimiento que implica, por tanto, el uso discrecional del tiempo de una persona, hay algunas formas de turismo que inevitablemente están vinculadas a obligaciones, como las necesidades del trabajo o de la salud". Esta última definición aporta el tema de las interacciones entre los diferentes componentes y el peso de los entornos en las actividades turísticas.

No importando la definición que se adopte, lo importante es dejar claro que el turismo es una actividad que en la actualidad involucra a una gran cantidad de personas en muy diferentes niveles de actividad y manifestaciones, tanto en las sociedades receptoras del mismo como también en las emisoras.

De este modo, para realizar un adecuado estudio del turismo y de toda la actividad que el mismo trae aparejada se hace necesario considerar los ejes (Ilamados TEMA) que le son esenciales 
como el tiempo, el espacio, las motivaciones y las actividades. Al mismo tiempo, cada uno de estos ejes está integrado por diferentes variables (Campodónico \& Chalar, 2010). Es de destacar que las actividades turísticas, motivadas por diversos factores, se llevan a cabo en determinado tiempo y al mismo tiempo en determinados espacios.

Es menester mencionar aquí los cambios que últimamente se están operando en el turismo tanto en sus modalidades, ya citadas en el punto uno de este trabajo, como en la visión y las actividades realizadas por los propios turistas. De esta manera, Davidow (1989), por ejemplo, está convencido de que el nuevo turismo de fines del siglo XX presenta una visión más amplia del lugar visitado, tanto desde el punto de vista económico, cultural como ecológico y de seguridad.

Finalmente, no queríamos dejar de lado tampoco el marco conceptual aquí utilizado, la teoría de Cohen (1988) según la cual el turismo no puede llegar a ser estereotipado debido a que cada experiencia vivida en el destino turístico es diferente para cada turista, lo cual permite ofrecer vivencias y lograr el cumplimiento de todas o la mayoría de sus expectativas.

\section{METODOLOGÍA UTILIZADA}

Para lograr los objetivos propuestos y poder confirmar o, en todo caso, refutar las hipótesis de partida, se optó por realizar una investigación de tipo exploratoria cuyo cometido es examinar un tema de investigación poco estudiado, no abordado con anterioridad, y al mismo tiempo de tipo descriptiva, a través de la cual se busca especificar las propiedades, las características y los perfiles de los estudiantes-turistas brasileños que realizan sus estadías de estudios de postgrado de Maestría y Doctorado en la UDE.

La aproximación al problema de estudio se realiza a través del método del estudio de caso, es decir, estudiando un caso individual (STAKE, 1995) en profundidad, utilizando para ello, en concreto, técnicas de obtención de información cuantitativas estadísticas, a las cuales se les aplica análisis de estadística descriptiva (Hernández Sampiere et alt., 2006). La elección de esta opción metodológica y de las técnicas acompañantes de la misma se deben a la conveniencia, por un lado, de tratar esta temática poco estudiada de una forma más profunda, lo que se logra a través del estudio de caso y de la utilización del enfoque metodológico cuantitativo en el curso de la investigación y el posterior análisis de las informaciones recogidas, y, por el otro, por considerarlo el más adecuado también para la comprobación de las hipótesis formuladas al inicio de la investigación, pues se requería para su comprobación, información confiable y que al mismo permitiera reproducir la investigación.

Las técnicas de obtención de datos utilizadas fueron:

- Estudios de fuentes secundarias estadísticas uruguayas y brasileñas destacando, entre otras: los anuarios de la Dirección Nacional de Migración (DNM), los datos estadísticos de la Cámara Uruguaya de Turismo (CAMTUR), anuarios del Ministerio de Turismo y Deporte (MINTURD), información sobre la población del Uruguay del Institutito Nacional de Estadística (INE), listados de estudiantes brasileños de la Facultad de Educación, de la Facultad de Derecho y de la Facultad de Ciencias Empresariales de la UDE, Anuarios estadísticos brasileños del Instituto Brasileño de Geografía y Estadística (IBGE).

- Encuesta aplicada a la totalidad de estudiantes brasileños de Maestría y Doctorado en la UDE -1614- cuya estadía por estudios se realizó durante la primera fase de los cursos en un período máximo de tres semanas del mes de enero de 2010.

Teniendo en cuenta de que se trata de un estudio más bien exploratorio con componentes descriptivos nos valemos, a la hora de analizar los resultados obtenidos en el trabajo de campo, de análisis de estadística descriptiva aplicada, en concreto, al estudio de los ejes TEMA, el cual se vio complementado con interpretaciones diversas versadas en el referencial teórico presentado en el punto anterior.

4 Sin embargo, el número de matriculados, según se puede observar en el cuadro 2, es superior. Este desfase en las cifras, se debe a dos hechos: la muestra equivale únicamente, como ya se especificó, a la estadía realizada durante el mes de enero de 2010, equivalente a la mitad de los alumnos brasileños de la UDE, y también al hecho de que algunos alumnos se matriculan y luego, por diferentes motivos, no pueden venir a realizar los cursos y lo hacen en otras fases de los mismos, volviéndose a matricular. Queremos aclarar también que de esos 161 alumnos, 159 habían nacido en Brasil y dos de ellos en otros países latinoamericanos aunque, según manifestaron, residen en el citado país desde su infancia. 


\section{LAS ESTADÍAS POR ESTUDIOS DE POSTGRADO DE MAESTRÍA Y DOCTORADO EN URUGUAY (2005-2010)}

La primera hipótesis de partida de este estudio afirmaba que las "estadías por estudios han experimentado el mayor aumento de todas las formas de turismo receptivo internacional no tradicional entre 2005 y 2010 en Uruguay". Veamos a continuación si esta afirmación se confirma o no.

Desde el año 2005 hasta el presente ${ }^{5}$ se realiza en Uruguay, por parte del MINTURD, una Encuesta de Turismo Receptivo ${ }^{6}$ en la cual se presentan cifras sobre la nacionalidad de nuestros visitantes, su lugar de residencia, puntos de ingreso al país, medios de transporte utilizados, destinos visitados, perfil de los visitantes, motivos del viaje, estadía media, alojamiento utilizado, divisas e ingresos por cruceros. Gracias a esta información y a otras complementarias se puede realizar un seguimiento del turismo receptivo en nuestro país en concreto en el periodo de estudio seleccionado en esta investigación (2005-2010).

Actualmente existen varias clasificaciones o tipologías adoptadas por el turismo entre las cuales se destacan aquellas que toman en consideración las formas de estadía adoptadas por el turismo receptivo internacional, como ya tuvimos ocasión de comentar con anterioridad. Para este estudio seguiremos de forma preferencial la adoptada por el MINTURD del Uruguay, la cual sigue, a grandes rasgos, la brindada por la OMT (2002). Ateniéndonos, justamente, a la utilizada en nuestro país, se pueden apreciar, en la tabla 1, los principales motivos de viaje esgrimidos por los turistas internacionales ingresados a nuestro país entre 2005 y 2010.

Tabla 1. Visitantes ingresados a Uruguay por año de ingreso y motivo del viaje (2005-2010)

\begin{tabular}{|l|l|l|l|l|l|l|}
\hline \multirow{2}{*}{ Motivo del viaje } & \multicolumn{7}{|c|}{ Año de } \\
\cline { 2 - 7 } & 2010 & 2009 & 2008 & 2007 & 2006 & 2005 \\
\hline $\begin{array}{l}\text { Visitas a familiares } \\
\text { o amigos }\end{array}$ & 573.880 & 469.172 & 355.891 & 386.800 & 371.353 & 364.636 \\
\hline Recreativo & 1.468 .834 & 1.290 .572 & 1.390 .978 & 1.188 .299 & 1.171 .577 & 1.242 .266 \\
\hline Negocios & 164.886 & 154.162 & 120.262 & 98.221 & 121.325 & 119.598 \\
\hline Deportivo & 12.172 & 13.623 & 8.783 & 5.170 & 8.429 & 6,962 \\
\hline Estudios & 42.290 & 20.008 & 8.504 & 12.876 & 19.129 & 17.809 \\
\hline Salud & 5.970 & 10.507 & 3.000 & 3.769 & 4.172 & 4.666 \\
\hline Tránsito & 84.655 & 89.024 & 76.540 & 72.939 & 84.327 & 117.798 \\
\hline Otros/sin datos & 54.789 & 51.712 & 33.926 & 47.207 & 44.028 & 43.314 \\
\hline Total & 2.407 .676 & 2.098 .780 & 1.997 .884 & 1.815 .281 & 1.824 .340 & 1.917 .049 \\
\hline
\end{tabular}

Fuente: Elaboración propia con datos tomados de la Encuesta de Turismo Receptivo (2005-2010) elaborada por el MINTURD (2011).

De las cifras contenidas en la tabla anterior (1) se puede desprender justamente un importante aumento en las formas no tradicionales de turismo receptivo internacional, destacando las entradas por estudios, las cuales sufrieron el mayor aumento de todas, llegando al 112,4\% en 2010 con respecto a 2009, por ejemplo. En las mismas se contemplan tanto las estadías por estudios de intercambio a nivel de grado a través de programas como Erasmus con Europa o Fulbraight con los Estados Unidos o del Mercosur Educacional con los países del Mercosur, estadías idiomáticas cuyo objetivo es aprender o perfeccionar el idioma español, asistencia a congresos o seminarios de breve duración y la realización de estudios de postgrado tanto en universidades públicas como privadas. Al tratarse de estadías muy variadas, en este estudio nos concentraremos únicamente en una de ellas, las estadías por estudios de postgrado en una institución universitaria uruguaya de carácter privado, la cual ofrece a estudiantes internacionales, mayoritariamente brasileños, la posibilidad de cursar estudios de Maestría y Doctorado, concentrados todos los cursos en dos estadías de tres semanas cada una durante dos años. El motivo de la elección de este tipo de estadía se debió a la particularidad de la misma: gran concentración en dos épocas del año coincidentes con los periodos

5 Hasta el momento solo se han publicado las cifras de 2005 hasta 2010 decidiendo, justamente, encuadrar nuestro estudio en este periodo de tiempo.

6 En años anteriores el llamado por entonces Ministerio de Turismo realizaba también encuestas sobre turismo receptivo en nuestro país, pero bajo otro formato. 
vacacionales de verano e invierno en Brasil, y por ser las únicas que aglutinan tanto a estudiantes de Maestría como de Doctorado con la única exigencia de poseer un título de grado de cualquier universidad cuyos estudios estén reconocidos en el país de origen del estudiante ${ }^{7}$, junto con un elevado gasto realizado durante sus seis semanas anuales de estadía superior a la media, como ya veremos, del turista brasileño.

La UDE ha puesto en funcionamiento, a partir de 2005, cursos de Maestría en Administración y de Maestría y Doctorado en Educación, y desde 2007 los cursos de Doctorado en Administración y Maestría en Derecho de las Relaciones Internacionales, destinados a alumnos brasileños o residentes en Brasil en condiciones de costear los mismos. Se optó por impartir los cursos únicamente en los meses de enero y julio, ya que en ambos se dan los grandes períodos vacacionales del país norteño de verano -enero- e invierno -julio-, gracias a los cuales estos estudiantes pueden ausentarse del país sin verse obligados a cambiar de residencia durante el periodo de sus estudios de postgrado de Maestría y Doctorado. A continuación se puede observar en la tabla 2 la evolución de la matrícula de estos alumnos en el periodo estudiado.

Tabla 2. Alumnos brasileños de postgrado de Maestría y Doctorado.

matriculados ${ }^{8}$

\begin{tabular}{|c|c|}
\hline Año & Cantidad de alumnos de Administración \\
\hline 2005 & 9 \\
\hline 2006 & 44 \\
\hline 2007 & 100 \\
\hline 2008 & 141 \\
\hline 2009 & 134 \\
\hline 2010 & 150 \\
\hline Año & Cantidad de alumnos de Educación \\
\hline 2005 & 33 \\
\hline 2006 & 95 \\
\hline 2007 & 131 \\
\hline 2008 & 119 \\
\hline 2009 & 112 \\
\hline 2010 & 101 \\
\hline Año & Cantidad de alumnos de Derecho \\
\hline 2007 & 27 \\
\hline 2008 & 97 \\
\hline 2009 & 85 \\
\hline 2010 & 90 \\
\hline \multicolumn{2}{|c|}{ Fuente: Elaboración propia con datos proporcionados por Decanato de FCCEE, FE y FD9. } \\
\hline \multicolumn{2}{|c|}{$\begin{array}{l}7 \text { Las otras universidades privadas del Uruguay localizadas en la zona metropolitana que cuentan con estudios de } \\
\text { postgrado -UM, UCU y ORT- no cuentan con estudios de Doctorado reconocidos aún por el Ministerio de Educación } \\
\text { y Cultura (MEC) y tampoco ofrecen estudios de Maestría con una concentración únicamente en dos periodos del año, } \\
\text { limitando con ello el número de estudiantes del exterior que deben permanecer por dos años en nuestro país para la } \\
\text { culminación de sus estudios. La universidad pública -Universidad de la República (UdelaR)- pone muchas veces como } \\
\text { condición para cursar los estudios de Maestría o Doctorado haber obtenido el título de grado en la propia universidad } \\
\text { (UdelaR), limitando con ello la llegada de alumnos internacionales. } \\
8 \text { Incluye a dos estudiantes con otras nacionalidades que residen en Brasil. } \\
9 \text { Facultad de Ciencias Empresariales (FCCEE.), Empresariales, Facultad de Educación (FE) y Facultad de Derecho (FD). }\end{array}$} \\
\hline
\end{tabular}




\section{Turismō}

En la tabla anterior (2) se puede observar que el número de estudiantes brasileños de postgrado de la UDE ha aumentado años tras año, lo mismo que ha venido ocurriendo con algunos altos y bajos con el grueso del turismo receptivo internacional procedente de Brasil (tabla 3).

Tabla 3. Ingreso de turistas brasileños por año 10

\begin{tabular}{|l|l|l|}
\hline Año ingreso & Total turistas brasileños & Total alumnos brasileños de la UDE ${ }^{2}$ \\
\hline 2005 & 197.672 & 42 \\
2006 & 228.353 & 139 \\
2007 & 286.319 & 328 \\
2008 & 297.332 & 357 \\
2009 & 263.414 & 331 \\
2010 & 376.894 & 341 \\
\hline
\end{tabular}

Fuente: Elaboración propia con datos de la DNM (2010) y del Decanato de FCCEE, FE y FD.

Sin embargo se debe manifestar que la excepción en este constante incremento del ingreso de turistas brasileños se produce en 2009 debido a los efectos de la crisis global de 2008. Aunque este descenso no se apreció entre quienes realizaron su estadía por estudios de postgrados de Maestría y Doctorado en la UDE, debido a la necesidad aún existente por parte de los profesionales brasileños de obtener una formación en postgrado que por diversos motivos, cuando no lo logran en su país de origen se ven en la necesidad de buscarla fuera.

Para comprender este aumento prácticamente constante en el ingreso de turistas brasileños y también de estudiantes brasileños de postgrado de la UDE, se deben tener en cuenta los siguientes factores: el continuado crecimiento del Producto Bruto Interno (PBI) de las economías latinoamericanas en general y de la brasileña en particular; la estabilidad económica y política de nuestro país; la existencia de buena infraestructura local; buen posicionamiento de Uruguay en distintos rankings mundiales, destacándose como uno de los países más seguros y con mayor calidad de vida de Latinoamérica (Silva y Gelabert, 2011); la transmisión de estas cualidades vividas en situ por los propios turistas a través de lo que se ha dado en llamar la teoría de las redes sociales (Massey, 1987) y la teoría del capital social (Bourdieu, 1980). Centrándonos en estas últimas, cuya importancia se evidencia en el continuado aumento de las estadías por estudios de postgrado de Maestría y Doctorado de estudiantes brasileños en la UDE, se puede afirmar que la primera de ellas considera a quienes se van de un país hacia otro, por distintos motivos, como actores racionales que persiguen objetivos y para alcanzarlos movilizan los recursos relacionales a su disposición, los cuales les sirven para conseguir información o elegir destino. El objetivo en este caso sería conseguir la titulación de postgrado de Maestría o Doctorado, y para ello se valen de la opinión de otros estudiantes - $54 \%$ - y de distinta información sobre los cursos, como bien se puede observar, en el gráfico 1.

10 No incluye a los turistas brasileños desembarcados en los puertos de Montevideo y Punta del Este en la temporada de cruceros que ascenderían a: temporada 2006-2007: 36.651; temporada 2007-2008: 89.159; temporada 2008-2009: 92.049; temporada 2009-2010: 154.061; temporada 2010-2011: 97.272 (MINTURD, 2011). 
Gráfico 1. Motivos de elección de los postgrados de la UDE por los estudiantes brasileños

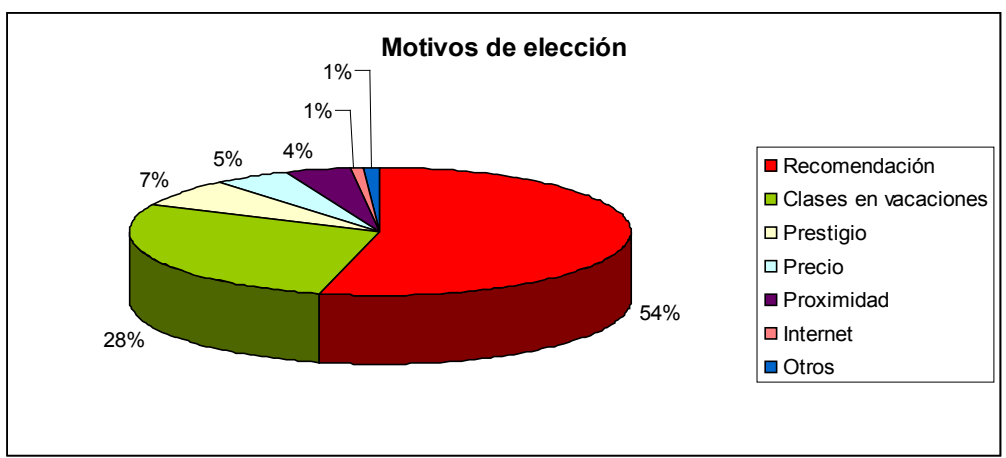

Fuente: Elaboración propia con datos de la encuesta, 2010.

Con relación al capital social, Bourdieu (1980) lo define como la suma de los recursos actuales y virtuales que un individuo o un grupo tiene disponibles por poseer una red duradera de relaciones de mutua vinculación recíproca con otros y de mutuo reconocimiento. El ser humano sería una especie de dimensión social que desarrolla relaciones con sus pares, las cuales les permiten lograr sus objetivos. En este caso, al encontrarse en el exterior por un mínimo de seis semanas al año durante dos años consecutivos (cuatro en el caso de quienes realizan la Maestría primero y luego el Doctorado), estos estudiantes generan toda una red de contactos de profesores, compañeros de clase, amigos y demás, que llevan consigo en el momento de la finalización de sus estudios y utilizan como sustento para mejorar su calidad de vida, ya sea generando proyectos de investigación en conjunto, publicaciones científicas, o accediendo a mejores oportunidades laborales. Por lo tanto, estarían adquiriendo un importante capital social, el cual puede redundar en un beneficio económico a largo plazo para ellos.

\section{PERFILES SOCIOECONÓMICOS DE LOS ESTUDIANTES DE POSTGRADO DE MAESTRÍA Y DOCTORADO}

La segunda hipótesis de partida de este estudio hacía referencia a que "los estudiantes brasileños que han realizado estudios de postgrado de Maestría y Doctorado en la UDE, entre 2005 y 2010 , ha efectuado un gasto medio mayor al realizado por el turista tradicional (brasileño) en nuestro país reflejado en rubros como alojamiento, alimentación, vestimenta, objetos artesanales, libros y electrónica, debido a que presentan una selectividad en su nivel educativo, socio-económico y de ingreso muy superior al de la media de la población residente en Brasil y al de la media de los turistas brasileños".

Para poder conocer la veracidad de la afirmación anterior nos hemos valido de las siguientes variables:

- Nivel de ingresos de los estudiantes brasileños

- Nivel de ingresos medios de la población brasileña

- Nivel de gasto medio en Uruguay durante la estadía

- Nivel de gasto total relacionado con los turistas en general que vienen en igual espacio de tiempo a Uruguay

Estas variables, como se puede observar, acompañan a uno de los citados ejes TEMA (Campodónico \& Chalar, 2010), en concreto el de las actividades realizadas por los turistas en el lugar de destino. Pero para ello es importante tener en cuenta también los otros ejes como son el tiempo, el espacio y las motivaciones. Con relación a estas últimas, ya las hemos mencionado en el punto anterior al hacer referencia a que la realización de los postgrados de la UDE son los que atraen al Uruguay a este grupo selecto de brasileños.

Para la comprobación de la hipótesis nombrada supra, se comenzó el análisis a partir de una presentación de los datos socioeconómicos de los estudiantes brasileños de postgrado ${ }^{11}$ de Maestría

11 Para ello se utilizan variables como: sexo, edad, estado civil... 
y Doctorado de la UDE para pasar luego a conocer, en detalle, todo lo relacionado al nivel de gastos realizados a través de diversos rubros.

\section{DATOS SOCIOECONÓMICOS DE LOS ESTUDIANTES BRASILEÑOS DE POSTGRADO DE MAESTRÍA Y DOCTORADO}

En este punto consideraremos las distintas variables socioeconómicas y también de carácter demográfico que nos llevan a conocer los perfiles no solo del turista medio brasileño en general sino de aquel que llega al país con la intención de realizar estadías por estudios, en este caso de postgrado de Maestría y Doctorado.

\section{LUGAR DE RESIDENCIA}

La República Federativa del Brasil se encuentra dividida, según la Resolución No 1 de la Comissão Nacional de Planejamento e Normas Geográficas do IBGE (Instituto Brasileiro de Geografia), del 8 de mayo de 1969, en cinco grandes regiones: Norte, Noreste, Centro Oeste, Sudeste y Sur. No todas ellas han alcanzado el mismo desarrollo económico y demográfico. De estas regiones, las más pobladas son y en este orden: Sudeste -la más desarrollada-, Noreste y Sur, y las menos, la Norte $^{12}$ y la Centro Oeste (IBGE, 2009).

Según los datos obtenidos en la encuesta aplicada, los alumnos de postgrado de Maestría y Doctorado brasileños de la UDE proceden, y en este orden, de las siguientes regiones: 25 de la Región Norte; 45 de la Noreste; 41 de la Sur; 35 de la Sudeste; 15 de la Centro Oeste (ENCUESTA, 2010). Se puede apreciar una ligera diferencia con relación a la distribución de la población brasileña a nivel general y también en la procedencia de la media de los turistas brasileños -mayoritariamente de la región Sur y Sudeste (MINTURD, 2011)-. La misma estaría relacionada con varios motivos. Uno de ellos: la región Sur es la más cercana a Montevideo y los gastos efectuados en locomoción son menores. Otro lo encontraríamos en la menor oportunidad de estudios en la región Norte y Noreste, pues los centros de estudios no suelen contar con los postgrados solicitados por los estudiantes brasileños de la UDE, mostrando con ello cómo el grupo de estudiantes de esa procedencia, sobre todo del Noreste -en donde la media de estudios es de 5,9 años contra la media del país de 7,1 (PNADIBGE, 2008)-, es privilegiado al poder continuar sus estudios y enfrentar los gastos provocados por su estadía en Uruguay. Y finalmente, otro motivo sería el funcionamiento de las redes sociales, que brindan información a conocidos o colegas sobre los estudios de postgrado de Maestría y Doctorado en la UDE en los períodos vacacionales, como ya se pudo observar en el gráfico 1.

Una aclaración a efectuar sobre estos datos es que no todos los estudiantes nacieron en los Estados o regiones actuales de residencia ${ }^{13}$, demostrando con ello la importancia de los movimientos migratorios internos de Brasil. De hecho, de la totalidad de los alumnos encuestados, el 40\% había cambiado de municipio y/o de estado, siguiendo con ello la tendencia general de la población brasileña. Durante el año 2008, las personas no naturales del municipio de residencia correspondían al $40,1 \%$ de la población del país y aquellas no naturales de los Estados en los cuales residían correspondían al 15,7\% (PNAD-IBGE, 2008).

\section{DATOS DE CARACTERIZACIÓN DEMOGRÁFICA}

En este punto analizaremos los datos demográficos de los alumnos brasileños de postgrado de Maestría y Doctorado de la UDE a través de las siguientes variables: edad, sexo y estado civil.

\section{EDAD}

La variable edad nos da información valiosa acerca de la etapa de la vida en la cual los estudiantes de postgrado de Maestría y Doctorado brasileños se plantean la necesidad de realizar cursos de

12 La región Norte es la que tiene la menor densidad demográfica de Brasil debido a varios factores.

13 Una de las preguntas de la encuesta pedía aclarar el lugar de nacimiento de los alumnos. 
especialización, ya sea para lograr una mejor inserción laboral o un ascenso en el trabajo actual, e incluso una mayor remuneración por el trabajo realizado. En todos los casos los postgrados son muy valorados, pues marcan un diferencial en conocimientos adquiridos, con respecto a quien no los ha realizado, pudiéndose ubicar en mejores posiciones laborales (Rodríguez, 2000). Incluso, en algunas circunstancias, como bien se ha detectado al realizar la encuesta, estudiantes de otras áreas del conocimiento diferentes a los postgrados ofertados por la UDE han decidido matricularse para lograr con ello insertarse en un mundo laboral ajeno a su especialidad de grado.

Gráfico 2. Distribución de los estudiantes brasileños de postgrado por edades

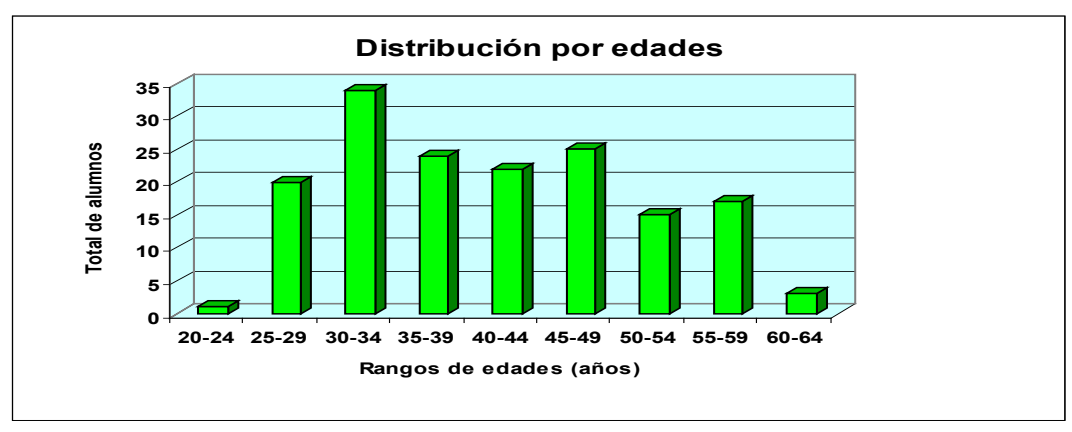

Fuente: Elaboración propia con datos de la encuesta, 2010.

Según consta en el gráfico anterior (2), la mayoría de los estudiantes tienen entre 30 y 35 años (24), 35 y 39 (24) y 45 y 49 años (25), representando estos rangos casi el $53 \%$ del total. Se trata entonces de personas de mediana edad, en las cuales la opción del postgrado está más en consonancia con los logros pretendidos en sus actuales trabajos. No se debe olvidar que en Brasil quien tenga una titulación de postgrado, fundamentalmente de Maestría y en el ámbito académico de Doctorado, recibirá un plus en su salario y puede aspirar incluso a obtener un ascenso en su trabajo, como ocurre en países como Estados Unidos. Según un estudio realizado por Fitzgerald en la University of Chicago Booth School of Business, en el cual se analiza el beneficio de un estudiante luego de realizar un MBA, se llegó a la conclusión de que el salario puede ascender casi a US\$1,5 millones a lo largo de toda su carrera profesional, estimada en 30 años (Vílchez, 2010). Fitzgerald asegura que, en un primer momento, las diferencias en salario son mínimas, pero se van incrementando con el tiempo. Al quinto año de haber finalizado el citado postgrado, por ejemplo, la brecha de ingresos alcanza los US\$ 8.300. En una década será de US\$ 20.400 y en 15 años alcanzará los US\$ 37.300. En el ejercicio final de su carrera, con 25 años, este importe sube a US\$ 92.500 (Vílchez, 2010). En definitiva, el citado estudio concluye que el impacto de realizar estudios superiores en los ingresos de un ejecutivo puede llegar al 900\% del dinero invertido, obteniendo US $\$ 13$ por cada dólar invertido. Vílchez (2010) asegura también, citando un estudio de Pino, subdirector académico de Centrum Católica de Perú, que "estudiar un MBA no necesariamente garantiza un aumento de sueldo, aunque podría aumentar las posibilidades de una persona de ingresar a una organización generándole más valor a la misma".

SEXO

A nivel general se observa una preponderancia de los alumnos del sexo masculino sobre los alumnos del sexo femenino: 90 hombres contra 71 mujeres. Esta diferencia contradice el perfil de estudiantes universitarios brasileños de grado presentado en un estudio (Osorio, Crippa y Loureiro, 2008) que al analizar la inserción de la mujer en la enseñanza superior brasileña, afirmó que la mismas representan un $55,8 \%$ contra el $44,2 \%$ de los hombres. En cambio, se discriminamos esta variable dicotómica por área de estudios (Administración, Educación y Derecho de las Relaciones Internacionales) observaremos algunas diferencias al respecto: se produce un neto predominio de los hombres sobre las mujeres en la Administración (49 contra 23) y el Derecho (19 contra 7), mientras que en Educación hay un claro predominio de las mujeres sobre los hombres (41 mujeres contra 22 hombres).

Nos encontramos con un neto predominio masculino en Administración y en Derecho de las Relaciones Internacionales. En cambio, en Educación, hay un claro predominio de las mujeres sobre los hombres. La explicación la encontraríamos en la predilección de las mujeres por 
los trabajos relacionados con el campo de la educación y, en general, de los hombres en la Administración y el Derecho, que se trasluce justamente en la concurrencia, según sexo, en los programas de postgrado.

\section{ESTADO CIVIL}

Esta variable la podríamos relacionar con la de edad. Si observamos nuevamente el gráfico de distribución por edades (2), la edad promedio de los estudiantes brasileños se ubica en una etapa de la vida en la cual las personas suelen plantearse un cambio de estado civil: de solteros a casados; de solteros a unión libre; de casados a divorciados, separados o viudos. De este modo, nos encontramos, de un total de 161 estudiantes, con: 81 estudiantes casados, 16 en unión libre, 11 divorciados, 5 separados, 3 viudos y 41 solteros.

Una conclusión similar muestra el estudio realizado por el FLACSO (1989) sobre la situación conyugal de la población brasileña gracias a los datos que tomaron de censos y encuestas realizados por el IBGE. De este modo, los estudiantes de postgrado brasileños que vienen a Uruguay siguen la tendencia general de la población brasileña.

\section{NIVEL DE GASTOS REALIZADOS DURANTE LAS ESTADÍAS POR ESTUDIOS Y VISITAS TURÍSTICAS}

La industria del turismo se ha convertido en estos momentos en la de mayor desarrollo en nuestro país, e inclusive en el año 2010 se convirtió también en la principal fuente de ingresos de divisas (SILVA y GELABERT, 2011). Realizando un paralelismo entre el ingreso de divisas procedentes por el rubro turismo y los principales bienes exportables se observa como el 69\% de las exportaciones de animales vivos y productos del reino animal son proporcionales al ingreso de divisas por el concepto de turismo, mientras que este último casi cuadriplica el total de exportaciones de lana y cuero registradas durante 2010 (MINTURD, 2011). Así, el ingreso bruto de divisas por turismo acumulado durante el año 2010 ascendió a US\$ 1.496 millones (MINTURD, 2011), un 14\% más que en 2009. Asimismo el ingreso neto, es decir, la diferencia producida entre el gasto turístico de los turistas ingresados a Uruguay en 2010 y el gasto turístico efectuado por residentes de nuestro país en turismo internacional, ascendió a los US\$ 1.077 millones, reflejando con ello una evolución del mismo (MINTURD, 2011).

Para tener una dimensión más clara de lo que estos ingresos representan en nuestro país, se realiza una comparación entre el gasto de consumo turístico o ingreso bruto en un período de un año y el PBI de la economía. Una vez efectuada la misma se ha verificado que para el año 2010 el gasto de Consumo Turístico representó el 3,7\% del PBI, cifra en aumento año tras año (MINTURD, 2011), a pesar de encontrarnos inmersos en medio de una crisis económica a nivel global.

Para medir el gasto total realizado por los estudiantes de postgrado brasileños de Maestría y Doctorado de la UDE se ha tenido en cuenta, en primer lugar, el gasto medio realizado por los turistas ingresados a nuestro país en los dos últimos años, desglosándolo en los siguientes rubros: alojamiento, alimentación, visitas turísticas y compras varias.

\section{GASTO MEDIO TOTAL POR ESTADÍA Y ANUAL}

El gasto medio total de los turistas en Uruguay varía según la procedencia de los mismos y el tiempo de estadía. A nivel general, el gasto total medio realizado por los turistas arribados a Uruguay durante los años 2008 y 2009 fue de US\$ 514,9 (MINTURD, 2010) y durante 2010 fue de US\$ 636 (MINTURD, 2011). En estas cifras no están incluidos los gastos efectuados por el turismo de cruceros, que ascendió durante 2010 a un total de US\$13.291.304. Con relación al gasto efectuado por el turista brasileño de esta última categoría, por ejemplo, el mismo pasó de los US\$ 6.329.764 en la temporada 2008-2009 a US\$ 10.961 .578 en la temporada 2009-2010 y a US\$ 6.907.191 para la temporada 2010-2011 (MINTURD, 2011). Como se puede apreciar, los brasileños desembarcados en Uruguay -tanto en el puerto de Montevideo como en el de Punta del Este- han efectuado la mitad de los gastos, a pesar de que son menos del 50\% del total de los cruceristas ${ }^{14}$,

14 Estamos hablando de 97.547 pasajeros brasileños de un total de 278.627 para la temporada de cruceros de 2010- 
demostrando de este modo el importante poder adquisitivo y el elevado gasto efectuado por ellos, muy similar, como veremos a continuación, al realizado por los estudiantes de postgrado de Maestría y Doctorado, con la salvedad de que estos últimos pernoctan un promedio de 20 días en Montevideo y los anteriores solo pasan el día.

Continuando con el análisis del gasto realizado por quienes llegan a nuestro país como turistas, descartando a los viajeros de los cruceros, son los estadounidenses quienes, en promedio, gastaron más, seguidos de los brasileños y luego de los chilenos, con un gasto diario de US\$ 72,5, US $\$ 69,9$ y US\$68,4 respectivamente (MINTURD, 2010). Si observamos, en cambio, el gasto total medio, en dólares americanos, realizado por los estudiantes brasileños de postgrado de Maestría y Doctorado de la UDE, comprobaremos una notable diferencia, siendo más elevado el de estos últimos. Así, por ejemplo, en cada estadía realizada por los estudiantes brasileños de postgrado de Maestría y Doctorado de la UDE (enero por un lado y julio por el otro), el gasto total ${ }^{15}$ efectuado por los mismos asciende a unos US\$242.000, aproximadamente (cerca de US\$500.000 al año), siendo el gasto medio realizado por cada uno de ellos de US\$1.515,62 ${ }^{16}$ (ENCUESTA, 2010) -cifra muy superior a la media del turista tradicional (US\$514,9 en 2009 y US\$ 636 durante 2010), prácticamente triplicándola: $295 \%$ más- y el gasto diario de US\$75,78 ${ }^{17}$ - por encima también al gasto medio de los turistas brasileños (US\$ 69,9)-.

La explicación la encontraríamos en el mayor tiempo de estadía -eje tiempo de los citados ejes TEMA- relacionada con los cursos -tres semanas en cada período vacacional-. Durante 2010, por ejemplo, la estadía promedio de los turistas internacionales en nuestro país ascendió a 6,5 días, lo que determinó una caída con respecto a la registrada en el año 2009 que había sido de 7,1 días (MINTURD, 2010 y 2011). Si nos atenemos a la nacionalidad de procedencia de los turistas se pueden apreciar las siguientes estadías promedio en días:

Tabla 4. Estadía media de los visitantes ingresados a Uruguay durante 2010 por Nacionalidad

\begin{tabular}{|l|l|}
\hline Nacionalidad & Promedio de días \\
\hline Argentinos & 6,3 \\
\hline Brasileños & 5,1 \\
\hline Paraguayos & 10,1 \\
\hline Chilenos & 6,8 \\
\hline Norteamericanos & 7,0 \\
\hline Resto de América & 5,7 \\
\hline Europeos & 8,3 \\
\hline Otras/Sin datos & 7,4 \\
\hline Uruguayos & 7,3 \\
\hline Promedio & 6,5 \\
\hline
\end{tabular}

Fuente: MINTURD, 2011.

Se puede apreciar como los brasileños en general se quedan, en promedio, 5,1 días frente, a los 5,7 días que se quedaban durante 2009 (MINTURD, 2010 y 2011), y por lo tanto los gastos realizados serán menores, ya que gastarán menos en alojamiento, alimentación, turismo y otros rubros. Cuanto mayor sea la estadía, mayores gastos se deberán afrontar. Al país le convienen estadías en promedio superiores a los 16 días, las cuales realizan tan solo el 11,2\% (MINTURD, 2011) de los turistas, entre los cuales se encuentran los estudiantes brasileños de postgrado de Maestría y Doctorado de la UDE, que llegan a los 20 días en promedio.

Otra explicación se encontraría también en el alto poder adquisitivo de estos estudiantes, ascendiendo a un total de 708.900 reales al mes (ENCUESTA, 2010), es decir unos 8.494.800 reales al año, aproximadamente, equivalentes a US\$395.05418 al mes y US\$4.740.652,64 al

2011 (MINTURD, 2011).

15 No se encuentran incluidos los gastos por matrículas que se deben abonar a la Universidad.

16 Anualmente serían unos US\$3.000.

17 Anualmente serían US $\$ 150$, ya que deben venir dos veces al año y en la muestra se tomaron solamente los datos de una sola de las estadías.

18 La conversión se realizó el día 24 de junio de 2010 con un tasa de cambio de 1 real = 0,55807 dólares americanos. 
año, respectivamente. El salario mínimo de Brasil se ubicaba en 2010 -fecha de la realización de la encuesta- en 510 reales (IBGE, 2010), equivalente a US $\$ 284,51$, y el salario promedio era de $1.358,43$ reales, es decir US $\$ 757,97$; el salario promedio mensual de estos estudiantes brasileños de postgrado de Maestría y Doctorado sería de $4.424,37$ reales (US\$2.468,17). Al mismo tiempo, el PBI per cápita llegó a la cifra de US\$ 9.400 (CIA World Factbook, 2010) disminuyendo un poco con relación a 2008 después de haber obtenido un largo ascenso durante el siglo XXI. Por lo tanto, los estudiantes brasileños de postgrado de Maestría y Doctorado de la UDE presentan un ingreso muy superior al de la media de la población de Brasil relacionado con los trabajos cualificados realizados por todos ellos tanto en empresas públicas como privadas o en centros de enseñanza terciaria, según manifestaron al aplicárseles la encuesta. Un importante porcentaje de los alumnos realiza más de una actividad remunerada, logrando con ello este nivel de ingresos más alto al de la población brasileña en general, lo cual les permite afrontar una mayor cantidad de gastos, como el presente de las estadías por estudios en el extranjero, en este caso, en Uruguay. De este modo, este grupo seguiría la tónica de la media de los turistas ingresados a nuestro país, los cuales se dedican a las siguientes actividades: $32,6 \%$ son profesionales $y / 0$ altos directivos; $23,0 \%$ son comerciantes 0 empresarios; $21,1 \%$ son empleados o funcionarios (MINTURD, 2009).

Discriminando los gastos realizados por los estudiantes brasileños de postgrado de Maestría y de Doctorado de la UDE, ya sea por rubro alojamiento, alimentación, turismo y otros gastos, se puede observar como los mismos varían durante sus tres semanas de estadía en cada período vacacional.

Gráfico 3. Gasto por rubros realizado por los estudiantes de postgrado de Maestría y Doctorado brasileños en porcentaje

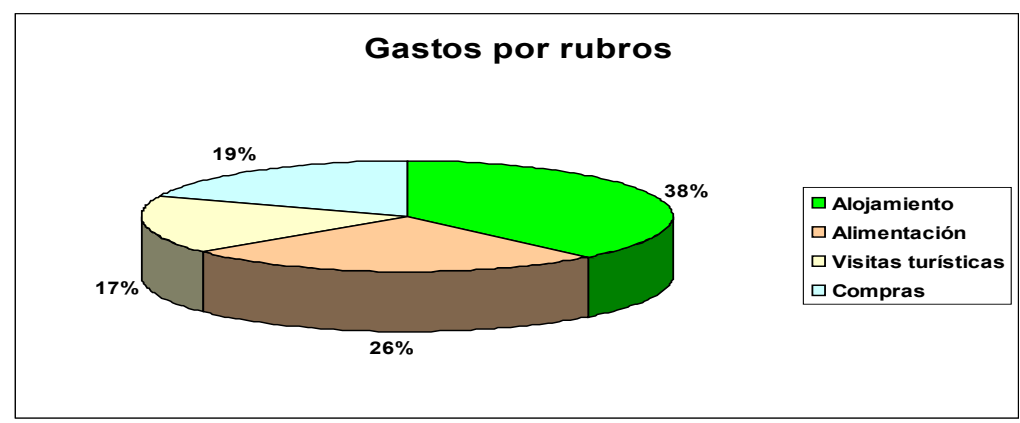

Fuente: Elaboración propia con datos de la encuesta, 2010.

A continuación, y siguiendo a grandes líneas la tónica de gastos de estos estudiantes brasileños, se puede observar como el grueso de los turistas internacionales ingresados al Uruguay durante 2010 realizaron también los mayores gastos de estadía en los siguientes rubros en consonancia con las actividades -eje TEMA- realizadas durante su estadía:

Tabla 5. Gastos realizados por los turistas ingresados a Uruguay durante 2010 en dólares americanos

\begin{tabular}{|l|l|l|}
\hline Rubro & Total & Porcentaje \\
\hline Alojamiento & 392.677 .076 & $26,6 \%$ \\
Alimentación & 362.791 .621 & $24,5 \%$ \\
Compras & 169.266 .595 & $11,5 \%$ \\
Transporte & 108.239 .209 & $7,3 \%$ \\
Tours & 9.393 .680 & $0,6 \%$ \\
Cultura y recreación & 25.493 .671 & $1,7 \%$ \\
Resto & 410.383 .790 & $27,8 \%$ \\
\hline Total: & 1.478 .245 .642 & $\mathbf{1 0 0}$ \\
\hline
\end{tabular}

Fuente: MINTURD, 2011. 
ALOJAMIENTO

El principal gasto afrontado por los turistas, cualquiera sea su origen, es el alojamiento, ascendiendo a unos US $\$ 392$ millones aproximadamente (26,6\% del gasto total) durante el año 2010 (MINTURD, 2011). Le siguen y por este orden: alimentación con US\$362 millones (24,5\%); compras con US\$ 169 millones (11,5\%); transporte con US\$117 millones (8\%); el resto de los gastos ascendió a US\$ 435 (29,5\%) durante el año 2010 (MINTURD, 2011).

En Uruguay existen diversas opciones a la hora de escoger un alojamiento: hoteles, hostales o albergues, pensiones, alojamientos institucionales, camping, casas de amigos o familiares, viviendas propias, viviendas arrendadas (MINTURD, 2011).

Tabla 6. Ingresos brutos por Turismo receptivo en millones de dólares según el alojamiento utilizado por los visitantes durante 2010

\begin{tabular}{|l|l|l|}
\hline Tipo de alojamiento & Total & Porcentaje \\
\hline Hotel & $558,508.501$ & $37,8 \%$ \\
\hline Vivienda propia & 258.509 .283 & $17,5 \%$ \\
\hline Vivienda arrendada & 239.084 .010 & $16,2 \%$ \\
\hline Vivienda flia./amigos & 371.964 .424 & $25,2 \%$ \\
\hline Camping & 9.665 .566 & $0,7 \%$ \\
\hline No utilizó & 979.062 & $0,1 \%$ \\
\hline Apart hotel & 19.730 .858 & $1,3 \%$ \\
\hline Tiempo compartido & 3.913 .041 & $0,3 \%$ \\
\hline Otros/Sin datos & 15.890 .897 & $1,1 \%$ \\
\hline Promedio & 6,5 & \\
\hline
\end{tabular}

Fuente: MINTURD, 2011.

Como se puede observar en la tabla anterior (6), el $37,8 \%$ de los turistas ingresados durante 2010 a nuestro país han optado por alojarse en hoteles de diferentes categorías, a saber: el 0,7\% de 1 estrella; el 9,7\% de 2 estrellas; el 39,4\% de 3 estrellas; el 35\% de 4 estrellas; el 7,6\% de 5 estrellas; y el $7,6 \%$ sin categorizar (MINTURD, 2011). Se observa claramente un predominio no solo en el tipo de alojamiento el hotel, sino también en aquel de mayores comodidades y por ende de mayor precio, teniendo por ello el turista que afrontar un mayor gasto durante su estadía en Uruguay. Esta tendencia la encontramos también en otros países como España, por ejemplo, en donde se está produciendo un importante aumento de las estadías en hoteles de 4 estrellas (Gonzáles y Talón, 2010).

Si nos atenemos únicamente a la elección realizada por los estudiantes brasileños de postgrado de Maestría y Doctorado de la UDE, nos encontraremos con las siguientes opciones escogidas:

Gráfico 4. Tipo de alojamiento de los estudiantes de postgrado de Maestría y Doctorado brasileños

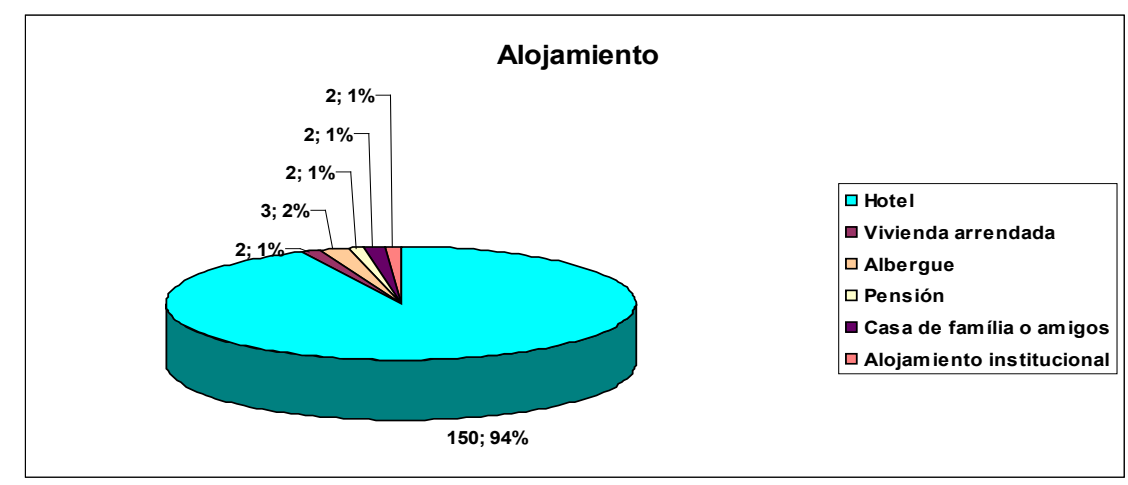

Fuente: Elaboración propia con datos obtenidos en la encuesta, 2010. 
Los estudiantes brasileños de postgrado de Maestría y Doctorado de la UDE optan también, como se puede apreciar en el gráfico anterior (4), por alojarse en hoteles, y dentro de estos en los de 3 y 4 estrellas. Un total de 79 estudiantes de postgrado se alojan en hoteles de 3 estrellas y 63 en los de 4 estrellas -el 95\% del total en ambas categorías-, y tan solo 6 en hoteles de 2 estrellas y 2 en hoteles de 1 estrella (ENCUESTA, 2010) en el espacio concreto -eje TEMA- de la ciudad de Montevideo, lugar en el cual realizan sus estudios de postgrado. Las preferencias por este tipo de hoteles están relacionadas con los convenios existentes entre los representantes de los postgrados en Brasil, las redes de contactos de los propios alumnos que se van recomendando unos a otros el lugar de alojamiento según el grado de satisfacción obtenido del mismo y también por el alto poder adquisitivo de los citados estudiantes. En la ciudad de Montevideo hay una amplia gama de hoteles ubicados en puntos estratégicos: playas, centro de la ciudad, Terminal de Tres Cruces. Las opciones manejadas por los estudiantes brasileños de postgrado de Maestría y Doctorado de la UDE se encuentran en la zona cercana a su lugar de estudios, es decir la sede central de la propia Universidad, ubicada en el Centro de Montevideo.

Un número menor de alumnos optan por alojarse en hostales o albergues, alojamientos institucionales, en casas de amigos o familiares o en viviendas arrendadas.

\section{ALIMENTACIÓN}

La alimentación es, según ya se comentó (véase tabla 6), el segundo rubro en el cual los turistas gastan más. Tanto el alojamiento como la alimentación son necesidades básicas de todo ser humano.

En el gráfico 3 se desprende como los estudiantes brasileños de postgrado de Maestría y Doctorado de la UDE siguen esta tónica, destinan el $26 \%$ del total de sus gastos, el cual ascendería, en cada una de las estadías, a unos US\$ 63.050 (Encuesta, 2010), en alimentación. En sus respectivos lugares de alojamiento suelen desayunar, pero el almuerzo, la merienda y la cena las realizan en diversos restaurantes u otros locales de comidas cercanos a las instalaciones de la sede de la propia Universidad. Gracias a ello el sector de restauración del centro de Montevideo se ha visto beneficiado durante los meses de enero y julio gracias a las estadías de estos estudiantes.

\section{VISITAS TURÍSTICAS Y OTROS GASTOS}

Acompañando a sus estadías por estudios, los estudiantes brasileños de postgrado de Maestría y Doctorado de la UDE realizan diversas visitas a los principales puntos turísticos no solo de la ciudad de Montevideo sino también del resto del país e incluso llegando hasta la Argentina, teniendo, por este motivo, una importancia fundamental también el eje TEMA del espacio.

El $87 \%$ contestó afirmativamente a la hora de preguntárseles si durante su última estadía habían realizado visitas turísticas, y tan solo el $13 \%$ respondió que no, aunque aclarando haberlas efectuado en estadías anteriores. Es importante también el gasto realizado en las mismas, el cual representa en cada una de las estadías un $17 \%$ del total, el cual equivaldría a unos US\$ 41.140.

Los lugares más visitados por los estudiantes brasileños de postgrado de Maestría y Doctorado de la UDE, además de los principales puntos turísticos de Montevideo, son y en este orden, siguiendo la misma tónica del turismo en general: Punta del Este, Colonia, Rocha, Canelones (zona de playas), Piriápolis, Salto y Minas. Incluso algunos estudiantes, más exactamente 15 de ellos (ENCUESTA, 2010) manifestaron haber visitado también Buenos Aires, aprovechando la cercanía con Colonia del Sacramento. Viendo la importancia de este nicho, empresas de turismo como Planet Travel se hacen presentes en las instalaciones de la UDE en cada estadía realizada por los estudiantes brasileños ofreciendo paquetes turísticos para visitar Punta del Este, Colonia y Buenos Aires, ya sea de un día o de un fin de semana, aprovechando los días de descanso.

Se pude comprobar así una preocupación o interés existente por los estudiantes de postgrado brasileños por tener un conocimiento más profundo de este lugar de destino -Montevideo- y de todos aquellos destacados como importantes centros turísticos, siguiendo la tendencia ya apuntada por autores como Davidow (1989).

En todos los lugares citados los estudiantes brasileños son atendidos por personal dedicado al sector servicios, el cual ha vivido un proceso de incremento en los últimos 10 años. Según la Encuesta 
Continua de Hogares (ECH, 2009) del Instituto Nacional de Estadística (INE) se desprende que la participación del empleo, únicamente en hoteles y restaurantes, en el total de puestos de trabajo a nivel nacional ha pasado del 2,2\% en 2001 al 2,7\% en el 2008. La citada encuesta menciona también que la actividad turística en su conjunto generó, durante 2008, un total de 125.240 puestos de trabajo, abarcando empleos tanto en servicios de alojamiento como de restaurantes, agencias de viajes y turismo, transporte, servicios culturales, esparcimiento en general y otros servicios turísticos (ECH, 2009). Esta última cifra continuó en crecimiento hasta ascender a un total de 133.663 personas ocupadas en actividades relacionadas con el sector turístico durante 2010 (MINTURD, 2011). El personal dedicado a estas actividades es fundamentalmente masculino $(61,3 \%$ contra el $38,7 \%$ de personal femenino) y joven, ubicándose el $24 \%$ del mismo en las franjas de edad comprendidas entre los 28 y los 37 años y el $21 \%$ entre 18 y 27 años (ECH, 2009).

Un indicador muy importante para medir la conformidad de los turistas que visitan nuestro país es el trato brindado por todo este personal del sector de servicios a los turistas en general. Una de las preguntas realizadas a los estudiantes brasileños de postgrado de Maestría y Doctorado de la UDE estaba relacionada con esto mismo. Se les pidió evaluar en una escala del 1 al 7 el trato recibido correspondiendo el número 1 a un trato totalmente inadecuado y el 7 a un trato de excelencia. Los resultados obtenidos se pueden observar en el siguiente gráfico.

Gráfico 5. Trato brindado por el personal de turismo a los estudiantes de postgrado de Maestría y Doctorado brasileños

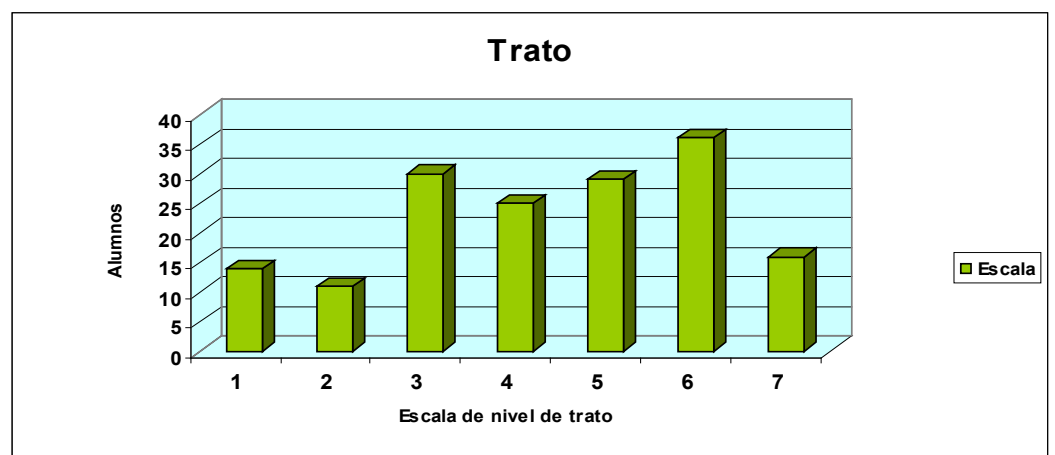

Fuente: Elaboración propia con datos de la encuesta, 2010.

El $48 \%$ de los entrevistados tiene una visión bastante positiva del trato recibido por el personal del sector turístico de nuestro país, pues a la hora de valorarlo le dieron una nota de 5, 6 y 7 . En cambio, casi un $35 \%$ de los mismos tiene una opinión bastante negativa del trato recibido, al cual le brindaron notas comprendidas entre el 1 y el 3 . Y un $17 \%$ de los entrevistados no tiene ni una opinión ni demasiado negativa ni demasiado positiva. Las autoridades turísticas deberían tomar nota al respecto y tratar de dirigir sus esfuerzos a mejorar la calidad de atención en el sector turístico, pues el mismo es un generador de divisas en constante aumento para nuestro país.

En la temporada 2009-2010 de cruceros se realizó una encuesta sobre los motivos de desagrado de los pasajeros desembarcados tanto en el puerto de Montevideo como en el de Punta del Este y tan solo 5.411 declararon como tal la mala atención en los servicios de un total de 292.048 (MINTURD, 2011). El número es bastante bajo si se lo compara con las cifras obtenidas en la encuesta realizada a los estudiantes de postgrado de Maestría y Doctorado brasileños. La explicación podría estar en que los turistas de cruceros visitan tanto Montevideo como Punta del Este únicamente por un día y no tienen un contacto tan fluido con los distintos servicios brindados al turista como el caso de los estudiantes brasileños que permanecen un promedio de 20 días, aproximadamente, en la capital del país.

La impresión que los turistas se llevan de un lugar es fundamental para que después ellos a su vez sean la llave de entrada de un mayor número de turistas. La cultura de la hospitalidad, como les gusta llamarla a los profesionales del turismo, "es una herramienta fundamental en la satisfacción del turista que nos visita. Todos los que han viajado recuerdan con especial atención el trato brindado por tal o cual empleado en un hotel, en la oficina de información turística, en la calle, en cómo se 
han preocupado para indicar tal o cual dirección y, lamentablemente para ese destino, también se recuerda con irritación el maltrato recibido. Si bien es una metáfora, no nos alejamos de la realidad al decir que la "llave" del turismo la tiene la comunidad residente que oficia de anfitriona para los visitantes" (Murray, 2012).

\section{OTROS GASTOS}

El rubro genérico de otros gastos engloba a todos aquellos gastos no comprendidos en los rubros anteriores también realizados por los turistas. Los principales serían y siguiendo el orden establecido por los estudiantes brasileños de postgrado de Maestría y Doctorado de la UDE: vestimenta, objetos artesanales, libros y electrónica. El gasto en vestimenta se ha incrementado, pues las estadías de los brasileños de postgrado de Maestría y Doctorado de la UDE coinciden con el período de rebajas en Montevideo. Además, es un atrayente la ropa de cuero fabricada en nuestro país no solo por el precio sino también por la calidad. La compra de objetos artesanales es una constante de los turistas, porque a través de ellos se recuerdan las estancias realizadas en los lugares visitados y además, algunos son exquisitas obras de arte. En cuanto a la compra de libros, la misma se debe, fundamentalmente a una necesidad por parte de los estudiantes brasileños de postgrado, debido a la obligatoriedad de leer bibliografía relacionada con sus temáticas de estudios en español, idioma en el cual deben presentar sus tesis tanto de Maestría como de Doctorado. En cada estadía, editoriales como Grupo Magro Editores y el Fondo de Cultura Universitaria se hacen presentes con stands en las diversas plantas de la UDE. Finalmente, se realizan también algunas compras, aunque no tan significativas como en los rubros anteriores, en electrónica.

\section{CONCLUSIONES}

Esta investigación ayudó a tener un mayor conocimiento del eje TEMA de las motivaciones que llevan a un turista a visitar un determinado lugar, en este caso Uruguay y en concreto la ciudad de Montevideo, pudiéndose observar un aumento entre quienes esgrimen, como se ha podido desprender de los datos estadísticos publicados por el MINTURD (2011), como motivos de ingreso, a lo largo del período estudiado (2005-2010) la realización de estudios, es decir uno no tradicional de visita al país, el cual tuvo un auge más que significativo a lo largo de 2010.

Junto con ello se ha podido comprobar también que el gasto medio de los estudiantes brasileños de postgrado de Maestría y Doctorado, en el caso concreto de la UDE -la muestra utilizada en el estudio- es superior, en un 295\%, al realizado por el turista brasileño tradicional en nuestro país reflejado en rubros como: alojamiento, alimentación, turismo tradicional, vestimenta, objetos artesanales, libros y electrónica. El alojamiento y la alimentación se Ilevan la mayor parte del presupuesto a gastar en estas estadías, debido a la media de días de estancia -tres semanas equivalentes a unos 20 días- seguidos por las visitas turísticas, fundamentales para tener un conocimiento más profundo del lugar de destino. Ello está relacionado con el alto poder adquisitivo de estos estudiantes en su país de origen, muy por encima de la media en un casi $330 \%$, el cual les permite afrontar los gastos no solo de alojamiento y alimentación sino también de turismo y otros rubros en su estadía en la ciudad de Montevideo durante el tiempo de realización de los cursos.

Se ha observado también que el estudiante brasileño de postgrado de Maestría y Doctorado es un turista más exigente en cuanto a la calidad y por ello demanda una atención, por parte del personal del sector turístico de nuestro país, más esmerada.

Finalmente, se puede afirmar que las estadías por estudios de postgrado de Maestría y Doctorado acompañadas por paseos turísticos realizadas por los estudiantes brasileños de la UDE representan una opción de turismo no tradicional dentro de las estadías por estudios en general, la cual le genera importantes ingresos económicos a nuestro país, por encima de la media realizada por el turista tradicional. De este modo, se puede observar entonces como las diferentes opciones o formas de turismo imperantes en la actualidad coexisten y al mismo se complementan (RIVAS MIRA, 2001). 
BRIDA, J. B., LANZILOTTA, B. y RISSO, W.A. Turismo y crecimiento económico: el caso de Uruguay. En Pasos. Revista de Turismo y Patrimonio Cultural, 3 (6), 2008, p. 481-492.

BORDIEU, P. Le Capital Social: Notes Provisoires. En : Actes de Recherche des Sciences Sociales, 31, Paris: 1980.

BULL, A. La economía del sector turístico. Madrid: Alianza, 1991.

CAMPODÓNICO, R. \& CHALAR, L. Turismo: una ciencia en construcción. En: Anais do VI Seminário de Pesquisa em Turismo do MERCOSUL- Saberes no turismo: Interfaces, Caxias do Sul, 2010, p. 1-15.

CAMPODÓNICO, R. \& CHALAR, L. Hacia la construcción del conocimiento en turismo. En: Estudios y perspectivas en turismo, 20 (6), [en línea] 2011. Disponible en: http://www.scielo.org.ar/scielo. php?script=sci_arttext\&pid=S1851-17322011000600005\&lng=en\&nrm=iso\&tlng=es. Consultado el 25 de agosto de 2013.

CAPANEGRA, C. La invención del desarrollo turístico, eje de una episteme de poder. En: 1er Congreso Latinoamericano de Historia Económica". CLADHE I - JUHE, Montevideo: 2007.

CÁRDENAS, F. Comercialización del turismo, determinación y análisis del mercado. México: Editorial Trillas, 1999.

COHEN, E. Authenticity and commoditization in tourism. En: Annals of Tourism Research. 15(3), 1988, P. 371-386.

COOPER, C., GILBERT, D. y WANHILL, S. Tourism: Principles and Practice. London: Pitman Publishing, 1998.

DAVIDOW, W. Total Customer Service. 10 Edición. New York: Editorial Harper, 1989.

DÍAZ PELLICER, L. El turismo receptivo en Uruguay (1930-1986). En: Serie Documentos de Trabajo, Facultad de Ciencias Empresariales, 64: 2004, p. 1-59.

GONZÁLEZ, L. Y TALÓN, P. Dirección hotelera. Operaciones y procesos, Madrid: Editorial Síntesis, 2010.

GURRÍA DI-BELL Di-Bella, M. Introducción al Turismo, México: Editorial Trillas, 1991.

HERNÁNDEZ SAMPIERI, R., FERNÁNDEZ COLLADO, C. y BAPTISTA LUCIO, P. Metodología de la investigación, 3era ed., México: McGraw-Hill, 2006.

KOTLER, P., BOWEN, J. y MAKENS, J. Marketing para turismo, 3era ed., Madrid: Pearson, Prentice Hall, 2004.

HUNZIKER, W. \& KRAPF, K. Grundriss der Allgemeinen Fremdenverkkhrsleher, Berna: Universidad de Berna, 1042.

MASSEY, D. S. Return to Aztlan. The social process of International Migrations from Western Mexico, Berkeley y Los Ángeles: University of California Press, 1987.

MANTERO, R., PERELMUTER, N. y SUEIRO, I. Determinantes económicas del turismo receptivo en Uruguay: ¿aporta información relevante un análisis desagregado? En: CINUE, Uruguay: 2004, p. 1: 1-20.

MURRAY, C. La "llave" del turismo. Buenos Aires: Universidad Nacional de Mar del Plata, 2012.

OMT Conceptos, definiciones y clasificaciones en las estadísticas de turismo. Manual Técnico, Madrid: 1995.

OMT Turismo. Panorama 2020. Volumen 7: Previsiones mundiales y perfiles de segmentos de mercado, Madrid: 2002.

OSÓRIO, F.L., CRIPPA J.A.S. y LOUREIRO, S.R. Escala para auto-avaliação ao falar em público (SSPS): adaptação transcultural e consistência interna da versão brasileira. En: Revista Psiquiatrica Clínica, 35(6), 2008, p. 207-11. 
RIVAS MIRA, F. A. Siete hipótesis sobre las grandes transformaciones del turismo internacional. En: APORTES, Revista mexicana de estudios sobre la Cuenca del Pacífico, 1 (2): 2007, p. 69-78.

RODRÍGUEZ DARIAS, A. J., SANTANA TALAVERA, A y DÍAZ RODRÍGUEZ, P. Las nuevas formas de turismo: causas y características. En: Revista Brasileira de Pesquisa em Turismo, 4 (3): 2010, p. 54-70.

SILVA, R. y GELABERT, L. El caso de Uruguay como destino turístico emergente, Madrid: IE Business School y OMT, 2010.

STAKE, R. The art of case research, California: Sage Publications, 1997.

STRADNER, J. Der Fremdenverkehr. Eine volkswirtschaftliche Studie. En: Ponencia presentada en las Primeras Jornadas del Turismo Alpino, Graz: 1884.

VALENCIA, J. Diccionario de términos turísticos. [en línea] 1989 Disponible en: <http://www.boletinturistico.com/index.php/diccionario?task=list\&glossid=1\&letter $=$ T\&page $=5>$. Consultado el 15 de mayo de 2013.

VÍLCHEZ, C. ¿Cuánto aumenta el sueldo tras realizar un MBA? Santiago de Chile: MBA \& Educación Ejecutiva, 2010.

VON SHULLERN, H. Fremdenverkehr und Volkwirtschaft. Jahrbuch für Nationalöconomie und Statistike. Jena, Vol III, f. 42. 4, 1911, p. 433-491

FUENTES PRIMARIAS

Encuesta realizada a 161 alumnos de postgrado de la UDE procedentes de Brasil. Montevideo: enero de 2010.

\section{FUENTES ESTADÍSTICAS DE SEGUNDA MANO}

Anuario 2009, Área de Investigación y Estadística del Ministerio de Turismo y Deporte [en línea]. 2010. Disponible en: http://www.turismo.gub.uyhttp://www.turismo.gub.uy. Consultado el 20 de mayo de 2010.

Anuario 2010, Área de Investigación y Estadística del Ministerio de Turismo y Deporte. [en línea]. 2011. Disponible en: http://www.turismo.gub.uyhttp://www.turismo.gub.uy. Consultado el 22 de marzo de 2011.

Anuario 2011, Área de Investigación y Estadística del Ministerio de Turismo y Deporte. [en línea]. 2012. Disponible en: http://www.turismo.gub.uyhttp://www.turismo.gub.uy. Consultado el 26 de febrero de 2012.

Anuarios de entradas y salidas de pasajeros de la Dirección Nacional de Migración (DNM) para los años 2008 y 2009 [en línea]. Consultado el 10 de abril de 2010. Disponible en: <http://www.dnm. minterior.gub.uy/anuarios>

Cancillería: hay 700.000 uruguayos en el exterior. En: Diario El País (29/10/08) [en línea]. Disponible en: http://www.elpais.com.uy/081029/pnacio-378440/nacional/cancilleria-hay-700000-uruguayos-enel-exterior. Consultado el 19 de diciembre de 2009.

CIA World Factbook [en línea]. 2010. Disponible en: https://www.cia.gov/library/publications/theworld-factbook/fields/2010.html. Consultado el 15 de mayo de 2010.

Datos y Cifras de la Organización Mundial del Turismo (WTO) [en línea]. 2008. Disponible en:< http: //www.unwt.facts/menu/HTML>. Consultado el 4 de octubre de 2009.

Encuesta Continua de Hogares del Instituto Nacional de Estadística (INE), Montevideo: INE, 2008.

Estadísticas de la Cámara de Turismo del Uruguay (CAMTUR) [en línea]. 2006. Disponible en: <http: //www.camtur.com.uy/estadisticas>. Consultado el 4 de octubre de 2009. 
Informe anual de turismo receptivo 2010, Ministerio de Turismo y Deporte (MINTURD) en base a datos de la Encuesta de Turismo Receptivo, Montevideo: MINTURD, 2011.

Listados de alumnos de Maestría y Doctorado de la UDE proporcionado por los Decanatos de: Facultad de Ciencias Empresariales; Facultad de Educación y Facultad de Derecho, 2010.

Pesquisa Nacional Por Amostra de Domicílios (PNAD). Síntese de Indicadores 2008. Instituto Brasileiro de Geografia e Estatística (IBGE), Rio de Janeiro: IBGE, 2008.

Plan de Marketing Estratégico y Operativo del Turismo de Uruguay. Diagnóstico, estrategias y acciones, 2009. Uruguay Natural, Montevideo, Ministerio de Turismo y Deporte (MINTURD), 2010.

PLANTUR 2009 - 2020 (Plan Nacional de Turismo Sostenible) del Ministerio de Turismo y Deporte (MINTURD) [en línea]. 2010. Disponible en:

http://apps.mintur.gub.uy/Plantur/index.php?option=com_content\&view=article\&id=10\&Itemid=35. Consultado el 20 de mayo de 2010.

\section{NOTAS}

1 En la estadística del MINTURD se han agregado otros motivos de viajes a partir de 2010 como las compras (1.456), segunda residencia (30.405) y religiosos (4.402).

2 Las estadísticas del MINTURD no discriminan por nacionalidad a los visitantes que ingresaron por estudios a nuestro país, así que aquí solo podremos brindar las cifras del total de estudiantes brasileños de la UDE y no del resto de casas de estudios o de quienes vinieron a un congreso, seminario, etc. 